\title{
A PRÁtica dA MEditAÇÃO MINDFULNESS NO ENSINO MÉDIO: UMA FERRAMENTA PARA A PROMOÇÃO DA SAÚDE E COMPLEMENTAÇÃO ACADÊMICO-FORMATIVA DOS ADOLESCENTES
}

\author{
THE PRACTICE OF MINDFULNESS MEDITATION IN HIGH SCHOOL: A TOOL \\ FOR HEALTH PROMOTION AND ACADEMIC-FORMATIVE \\ COMPLEMENTATION OF ADOLESCENTS
}

DOI: http://dx.doi.org/10.23926/RPD.2526-2149.2019.v4.n2.p524-545.id506

\section{Anderson Augusto Ribeiro \\ Mestre em Ensino \\ (IFMT\UNIC) \\ anderson.ribeiro@blv.ifmt.e \\ du.br}

\section{Cleonice Terezinha \\ Fernandes}

Doutora em Ciências da

Motricidade al (UTAD/PT)

Pós-Doutoranda na

Universidade de Huelva -

Espanha (UHU)

cleo_terezinha@hotmail.com

\section{Maria Isabel Martins \\ Mourão Carvalhal \\ Doutora em Ciências da \\ Motricidade (UTAD/PT) \\ mimc@utad.pt}

\section{Edgar Nascimento}

Doutor em Engenharia

Elétrica (UNESP)

edgar.nascimento@blv.ifmt edu.br
Resumo: Este estudo é um recorte da pesquisa, em nível de mestrado, "Influência de um programa de consciência corporal em estudantes do ensino médio", que foi realizada no IFMT Campus Cuiabá - Bela Vista, cujo objetivo é verificar a influência da prática do mindfulness para a promoção da saúde e complementação acadêmico-formativa de adolescentes. Neste trabalho, evidenciaram-se resultados preliminares e as percepções dos estudantes acerca de tal prática na escola. De tipologia pesquisa-ação com abordagem qualitativo-quantitativa, o estudo se desenvolveu entre março e maio de 2019. Para a produção de dados, foram utilizados questionários e protocolos específicos da área da Educação Física, sendo tais instrumentos aplicados nas fases pré e pós-intervenções. O programa se efetivou com o desenvolvimento de vivências de mindfulness que promoviam uma profunda reflexão sobre o corpo-mente, ocorrendo na escola e nas residências de cada participante. Resultados preliminares demonstraram que após quatro seções presenciais, aliadas a oito semanas consecutivas de práticas de mindfulness domiciliar, foi possível verificar uma melhora na percepção e conduta que estes adolescentes tiveram para com os seus corpos e ações diárias. Por fim, pode-se considerar que tais vivências foram ferramentas essenciais para uma visão mais contextualizada, acerca da relevância das intervenções sistêmicas nos fatores biopsicossociais e acadêmico-formativos.

Palavras-chave: Mindfulness; Neurociência; Ensino-aprendizagem; Embodied cognition.

\begin{abstract}
This article is an excerpt from a master's level research, "Influence of a Body Awareness Program with High School Students", which was conducted at IFMT Campus Cuiabá - Bela Vista and aims to verify the influence of mindfulness practice for health promotion and academicformative complementation of adolescents. In this paper we pointed preliminary results and students' perceptions about such practice at school. From an action research typology with a qualitative and quantitative approach, the study was developed from March to May 2019.For the production of data, we used questionnaires and specific protocols of the Physical Education area, being these instruments applied in the pre and postintervention phases. The program was implemented with the development of mindfulness experiences that promoted deep reflections about mind-body that occurred at school and at each participant's house. Preliminary results showed that after four face-to-face sections, combined with eight consecutive weeks of home mindfulness practices, it was possible to verify an improvement in the perception and conduct that these adolescents had with their bodies and their daily actions. Finally, we consider that these experiences were essential tools for a more contextualized view about the relevance of systemic interventions in biopsychosocial and academic-formative factors.
\end{abstract}

Keywords: Mindfulness; Neuroscience; Teaching and learning; Embodied cognition. 


\section{INTRODUÇÃO}

Atualmente é comum verificar nas escolas que os adolescentes/jovens se sintam engajados num processo de racionalidade-reativa, que é consolidado pelo cotidiano tecnológico-virtual no qual eles vivem. Logo, também é observável que este público se encontra imerso num processo em que se assumem condutas de omissão quanto às reflexões/análises de suas próprias atitudes, e, consequentemente, de sua consciência corporal, proporcionando situações diárias totalmente opostas àquelas que realmente podem lhes proporcionar um equilíbrio corpo-mente eficaz e saudável.

Por isso, neste estudo, procurou-se desenvolver atividades numa perspectiva somática em ambiente escolar, com os objetivos de prevenir a saúde geral desses estudantes, bem como complementar a sua formação acadêmica, por meio de práticas que possam melhorar sua integração junto ao processo educacional. Logo, para este artigo, foi utilizada a prática interventiva de meditação mindfulness, que é conceituada por manter o praticante atento, de modo consciente ao estado corporal e à realidade, e sem julgamentos prévios das situações que o permeiam.

De acordo com esta perspectiva, pode-se dizer que o mindfulness se refere a um estado mental que se caracteriza pela autorregulação da atenção para a experiência presente, numa atitude aberta, de curiosidade, ampla e tolerante, dirigida a todos os fenômenos que se manifestam na mente consciente, ou seja, todo tipo de pensamentos, fantasias, recordações, sensações e emoções percebidas no campo de atenção são aceitas exatamente como são, sem apego (geralmente para as coisas que se julgam boas) e aversão àquelas consideradas más (KABAT-ZINN, 1990).

Desse modo, esta ação caracterizou-se como uma possibilidade de se inserir novas atuações no campo pedagógico, no qual se pode agir coletivamente, com a finalidade de promover mais experiências e elementos preventivos perante o cotidiano contemporâneo em que se vive, o qual traz novas tecnologias e saberes que se acumulam e transformam toda a sociedade de maneira repentina, seja benéfica ou maleficamente.

Neste prisma, as escolas, seus atores e projetos, figuram-se como eixos norteadores para os processos de novas experiências, adaptações, interlocuções, aprendizados e disseminações, para que, a partir de tais contextos, novos caminhos e condutas se fundam para que os objetivos escolares sejam atingidos plenamente.

Assim se prospecta endossar a apropriação de um protagonismo cinético-reflexivoconsciente junto aos alunos de nível médio de uma escola profissionalizante, embasados nas 
concepções das neurociências e do paradigma Embodied cognition $^{l}$, atuando dentro e fora das escolas, pautados na prática de vivências somáticas individuais e coletivas, possibilitando reflexões/ponderações contínuas frente às situações que se relacionam à própria existência, como seres agentes no mundo.

Entende-se que a partir da adoção desse tipo de prática/comportamento, será encaminhado um propenso cenário de equilíbrio pessoal e cognitivo no meio educacional, que poderá se mostrar extremamente salutar frente à diminuição dos riscos biopsicossociais aos quais se estão expostos, bem como para a evolução dos processos pedagógicos tradicionalistas que ainda são vivencidos atualmente.

Enfim, com a intenção de se promover um espaço acadêmico mais tranquilo, saudável e eficaz, buscou-se neste estudo tornar os discentes mais conscientes e participativos por meio do desenvolvimento de ações como esta, que têm a real possibilidade de inferir positivamente e diretamente na estrutura vital desses jovens, principalmente no que diz respeito à açãoreflexão num espaço comum. É, pois, uma de suas obrigações proporcionar a disseminação e a apreensão dos saberes a partir daquilo que é vivenciado, contribuindo para o desenvolvimento autônomo e integral de seus agentes.

\section{REFERENCIAL TEÓRICO}

De acordo com Levisky (1995), com a chegada da puberdade, os corpos dos adolescentes sofrem diversas transformações biológicas, sendo estes surpreendidos fortemente por impulsos sexuais, revoltas, agressividade, timidez, apatia, além de conflitos afetivos que são característicos nesta fase da vida.

Outros artifícios reacionais surgem com características evidentes e repetitivas, como por exemplo: relativos à vergonha, ao medo, ao isolamento e outras alterações de ordem psicossociais. Trata-se, portanto, de um período ímpar que necessita ser compreendido, acompanhado e dialogado, com muita atenção por todos aqueles que circundam esses adolescentes.

Neste sentido, sabe-se que todos os processos de reformulações biopsicossociais da adolescência citados anteriormente iniciam-se no cérebro, mais precisamente no hipotálamo, que tem a função de regular os desencadeamentos dessas transformações, sejam elas: físicas, fisiológicas, cognitivas, emocionais e sociais. Portanto, é natural que ocorram alterações e

\footnotetext{
${ }^{1}$ Esta teoria afirma que o nosso conhecimento se forma por meio da interação de estados sensoriais e estados motores, que ocorrem juntos com as experiências que vivemos e as emoções que sentimos diariamente. <https://www.institutoconectomus.com.br/o-que-e-embodiment/>
} 
reorganizações químicas e funcionais a todo o complexo sistema humano, que passa por esse período de transição da juventude, para se estabilizar posteriormente na vida adulta (HERCULANO-HOUZEL, 2013).

[...] a adolescência cria uma classe de indivíduos que se associam e enfrentam os mesmos desafios, ambientais, mentais e sociais, cuja superação acaba por torná-los aptos a sobreviver longe dos pais ou responsáveis. O gosto por riscos, o distanciamento da família, a formação de novas amizades e o desenvolvimento cognitivo e emocional que caracterizam o adolescente hoje são vistos pela neurociência como etapas necessárias à conquista da independência adulta, e tudo orquestrado por um só maestro: o cérebro (HERCULANO-HOUZEL, 2013, p. 39).

Na perspectiva da neurociência, com exceção da ambição sexual, é pouco provável que as variações hormonais encontrem-se associadas com as vastas mudanças comportamentais e cognitivas da adolescência. Deste modo, é mais previsível que o comportamento peculiar dessa fase seja produto da modificação estrutural e funcional do próprio cérebro.

Nota-se, portanto, que cérebro do adolescente age a partir de um emaranhado de sensações e comportamentos impulsivos, em que este se maturará completamente por volta dos vinte e um anos de idade, no momento em que córtex pré-frontal estará formado por completo, oportunizando, então, tomadas de decisões mais coerentes, juntamente com o aperfeiçoamento do controle inibitório ${ }^{2}$ (JENSEN, 2016).

Herculano-Houzel (2013) ainda revela que todas essas ações, denominadas “comportamentos motivados", podem ser esclarecidas devido ao embotamento ${ }^{3}$ do sistema de recompensa ${ }^{4}$ adolescente. Essa condição concebe ao jovem a possibilidade de afastar-se de seus hábitos antigos de modo abrupto, transformando-os na sequência em hábitos desinteressantes, na procura incessante por novos prazeres que podem ocorrer em diversos níveis.

Assim, esses conjuntos de modificações comportamentais são um marco da transição da vida adolescente para a vida adulta, que se constitui naturalmente, afastando-os paulatinamente do aconchego familiar, para que então eles possam, através das vivências corporais já experimentadas em diversos meios, se inserirem na sociedade de maneira autônoma, responsável, cientes dos valores éticos e morais, bem como inteirados de suas responsabilidades.

\footnotetext{
${ }^{2}$ É a habilidade para inibir ou controlar respostas impulsivas (ou automáticas) e criar réplicas usando a atenção e o raciocínio. Esta habilidade cognitiva é uma de nossas funções executivas e contribui para a antecipação, o planejamento e a definição de objetivos. 〈https://www.cognifit.com/br/habilidade-cognitiva/inibicao >

${ }^{3}$ É um tipo de comportamento em que o indivíduo se apresenta com dificuldades em expressar emoções e sentimentos.

${ }^{4}$ É um mecanismo que o cérebro recebe quando detecta sensações de prazer, sejam elas quais forem; inclusive vício em eletrônicos e drogas, comer chocolate, e é claro, o próprio prazer sexual.
} 
Por ser injusta e estressante para tantos, a vida em sociedade pode, de fato, ser um problema para o sistema de recompensa adolescente. A boa notícia é que a vida social bem-ajustada, que dá ao adolescente um bom status social, tem o efeito contrário: aumenta o número de receptores para dopamina no sistema de recompensa de quem está por cima [...] À medida que o indivíduo assume o controle do seu ambiente, do seu direito de ir e vir, de suas fontes de comida e sexo, das suas próprias decisões, o sistema dopaminérgico se fortalece. Isso contribui para o bem-estar do indivíduo, agora dono de um sistema de recompensa mais facilmente ativável, e ainda tem outra consequência bem-vinda: o risco de vício em drogas fica diminuído. Bem também faz outro prazer adolescente da vida em sociedades urbanas: o exercício físico, que proporciona ativação do sistema de recompensa através da liberação de opióides como a endorfina, e parece contribuir para o fortalecimento da atividade dopaminérgica do sistema (HERCULANO-HOUZEL, 2013, p. 74).

Ao se observar por outra perspectiva, pode-se perceber hoje que os adolescentes estão inquietos diante das matérias relativas a si próprios, em face ao mundo contemporâneo em que transitam. Estes corpos parecem estar num contínuo processo de transformação demasiadamente dinâmico e nocivo, com características irreflexivas, consolidadas por ações repentinas e reativas na sociedade.

Neste sentido, Gebara et al (1992) descrevem:

Há, também, esta coisa perversa que vem sendo praticada pelo consumismo e que consiste em transfazer o corpo em mercadoria, instalando-o como mais uma das levianas modas da sociedade do lucro. Súbito, ficou na "moda" inquietar-nos com a temática corporal, como se só recentemente houvéssemos passado a ser corpos no mundo. Todos podemos ver as muitas explorações de marketing sobre este assunto, que têm resultado em rios de dinheiro e oceanos de distorções compreensivas (GEBARA et al., 1992, p. 72).

Concomitantemente a esta realidade, é comum encontrar nas escolas adolescentes sofrendo com distúrbios psicossomáticos, como ansiedade, depressão, isolamento, estresse e frustrações generalizadas, devido ao fato de se sentirem pressionados nesta fase da vida por diversos padrões existentes na sociedade, causando por consequência uma ininterrupta segmentação corpo-sujeito. Evidencia-se, então, que a totalidade de problemas relacionados ao cerne biológico é multilateral, e o corpo acaba por concentrar e sofrer influências a partir das mais diversas fontes, formas e ângulos.

Na visão de Kristeva (1995), os seres humanos estão se desfazendo de suas próprias identidades, pois afastam seus corpos de ambientes e atitudes cotidianas que promovam a reflexão intrapessoal e um bem-estar social. Como consequência, observa-se o aumento da intolerância (violência) em diversos segmentos da sociedade, inclusive nas escolas, além dos hábitos corriqueiros de consumo de substâncias lícitas (álcool, tabaco e os fármacos), e até mesmo, dos produtos ilícitos, como as drogas e seus subprodutos.

Vive-se, portanto, num mundo que potencializa e dissemina o prazer em detrimento da consciência corporal e espiritual, por exemplo, onde a mídia, por meio da evolução tecnológica, 
impõe felicidades instantâneas às pessoas de variadas faixas etárias, mas que, em especial, atingem ferozmente os adolescentes/jovens. Estes, por vezes, não conseguem enxergar a superficialidade e a intenção que esses meios de comunicação dissipam, gerando por consequência identidades pormenorizadas, que se constituem como mitos, de caráter extremamente raso e flexível, que agem abstratamente de acordo com as ocasiões do dia a dia que lhes convém.

Por esses motivos é interessante desenvolver/manter atitudes e ambientes de enfrentamento, que promovam a sensibilidade e a vivência do corpo integral, que atua em diversos contextos da sociedade, principalmente com relação ao público adolescente/jovem. Neste sentido, o intuito principal foi introduzir e acompanhar o impacto que a prática da meditação mindfulness pode gerar nos alunos do nível médio de ensino e mensurar a sua possível influência no ambiente escolar destes.

Esse tipo de conduta ajudará a minimizar os subterfúgios superficiais e viciantes, em prol de um comportamento mais reflexivo e acolhedor, sendo este capaz de transcender emoções positivas para outras pessoas e, consequentemente, gerar uma retroalimentação.

A partir disso, entende-se que o estabelecimento e o desenvolvimento de práticas de cunho somático-reflexivo nas escolas, que auxiliem as práticas pedagógicas formais de ensino, através da disciplina de Educação Física e áreas afins, surgem como propostas de intervenção pessoal/coletiva e pedagógica, se configurando como indispensáveis neste cenário. Pode-se, pois, a partir da pluralidade de práticas e concepções dos sujeitos, e das inúmeras possibilidades que estes corpos podem experimentar, produzir e atingir um amplo estado de consciência, que fortalecerá toda a gama de sentir, pensar e agir, em contraposição às situações cotidianas que têm nos assolado ao longo dos últimos anos.

Em face desta realidade, Moraes (2005) relata que:

A dificuldade de trabalhar dentro de uma visão sistêmica, com um enfoque de totalidade, tem ocasionado poucos avanços em direção à solução de alguns problemas educacionais, o que vem colaborando para o prevalecimento das atuais taxas de analfabetismo, evasão, repetência, baixa qualidade do ensino e outras tantas mazelas (MORAES, 2005, p.86).

Portanto, espera-se que concepções e abordagens complementares no campo educacional possam se consolidar com a finalidade de se romper com esses estímulos externos exacerbados que arraigam nossos corpos diariamente. Desse modo, pode-se conseguir estagnar os paradigmas tradicionais do ensino motivados por ações mais humanizantes, democráticas, 
diversificadas e articuladas, por meio do desenvolvimento de multitarefas nas dimensões afetivas, cognitivas e socioculturais, junto aos estudantes.

E para que estas novas ações se constituam, visualiza-se a possibilidade de se intensificar ações pautadas na prática da meditação mindfulness ao contexto educacional, observando seu rico alcance sob uma perspectiva integral de ser humano, para serem desenvolvidas continuamente durante o ano letivo. Essa prática possivelmente repercutirá positivamente nos processos acadêmico-formativos dos adolescentes/jovens, subsidiando, assim, a própria existencialidade autônoma desses jovens na escola e sociedade.

Contextualizando primeiramente a meditação, esse tipo de prática, oriunda das tradições orientais, é uma prática antiga, relacionada às ideologias do yoga e do budismo. Esta atualmente se desenvolve em diversas partes do mundo, não estando obrigatoriamente ligada a uma religião ou filosofia, mas a uma vivência que trabalha o corpo e o espírito integradamente (LEVINE, 2011).

Tecnicamente a meditação é considerada um artifício atencional consciente, que possui diversos métodos para que seja alcançado o ápice dessa atenção desejada, como por exemplo: um som, um objeto, uma tema ou a própria respiração (SHAPIRO e WALSH, 1984).

Na concepção de Newberg e Iversen (2003), os processos meditativos podem gerar mudanças nos aspectos cognitivos, sensoriais, afetivos, e também alterações fisiológicas hormonais, o que pode desencadear posteriormente mais atitudes autônomas dos indivíduos que os praticam.

Nesta temática, a neurociência também influi e se destaca devido algumas contribuições já realizadas, demonstrando, por meio de sofisticadas aparelhagens e técnicas, que o córtex préfrontal $^{5}$ e o cíngulo anterior ${ }^{6}$, por exemplo, são partes do cérebro que são ativadas quando o sujeito pratica a meditação (NEWBERG; IVERSEN, 2003).

Para Lazar et al. (2005), outras descobertas demonstram que as regiões cerebrais associadas à atenção e processamento sensorial, incluindo o córtex pré-frontal e a ínsula ${ }^{7}$

\footnotetext{
${ }^{5}$ Esta região cerebral está relacionada ao planejamento de comportamentos e pensamentos complexos, expressão da personalidade, tomadas de decisões e modulação de comportamento social. A atividade básica dessa região é resultado de pensamentos e ações em acordo com metas internas. Os cientistas chamam as tarefas realizadas pelo córtex pré-frontal de "funções executivas" (HERCULANO-HOUZEL, 2013).

${ }^{6}$ É uma longa estrutura localizada na parte frontal do nosso cérebro na linha medial, que se caracteriza por um aglomerado de fibras de substância branca em formato de $\mathrm{C}$ com axônios fazendo comunicação entre o sistema límbico (controle mais emocional) e o córtex (controle mais racional). Tem funções na evocação de memórias e na aprendizagem (HERCULANO-HOUZEL, 2013).

${ }^{7}$ É um lobo profundo, situado no fundo do sulco lateral, no encéfalo. A ínsula tem forma triangular com vértice ínfero-anterior, está separada dos lobos vizinhos por sulcos pré-insulares. Possui cinco giros (curtos e longos).
} 
anterior direita, se tornaram mais espessas em indivíduos que praticavam meditação em comparação ao grupo controle, até mesmo quando avaliados praticantes com idades mais avançadas, validando que o meditar pode equilibrar o afinamento cortical com o passar do tempo.

Por consequência da prática da meditação aliada às suas modificações biológicas já constatadas, ocorre simultaneamente a liberação dos neurotransmissores no organismo, tendo como exemplos: a serotonina, a acetilcolina e dopamina, que atingem rapidamente o sistema nervoso provocando sensação de prazer, bem-estar e relaxamento, quando presentes em níveis pertinentes (DANUCALOV e SIMÕES, 2006).

Dessa forma, é possível compreender que a prática meditativa auxilia eficazmente no combate a alguns fatores de risco que se apresentam, como o estresse, a ansiedade e a depressão, bem como no enfrentamento das dores crônicas e outros problemas de saúde (VALE, 2006; VALLATH, 2010).

Newberg e Iversen (2003) ainda colaboram coadunando com as modificações fisiológicas citadas anteriormente, e acrescentam que ocorrem aumentos nas concentrações de séricas dos neurotransmissores e substâncias neuroquímicas no organismo, ao passo que índices de cortisol e noradrenalina baixam seus níveis durante as práticas de meditação.

Neste contexto, a Organização Mundial da Saúde (OMS, 2005) reconhece e incentiva as práticas de terapias alternativas como a meditação, caracterizando-as como um método para a prevenção de doenças, promovendo a melhora da criatividade, diminuição da ansiedade e do estresse e estabelecendo uma comunhão espiritual com o organismo e a natureza.

Marques, Rocha e Flores (2015) indicam a experimentação da meditação, pois:

Meditar proporciona ampliação das capacidades perceptivas e interpretativas, pois envolve contemplação, avaliação e tomada de decisão; amplia o poder criativo e renova o sentido de pertencimento ao coletivo. A meditação é a realização da vida presente, do agora construído historicamente e propicia o autoconhecimento, contribuindo para a formação plena do sujeito. (ROCHA; FLORES; MARQUES, 2015, p. 408).

Contudo, diante dos vastos benefícios que a meditação tem trazido à esfera da saúde, como atividade preventiva às doenças psicossomáticas, justifica-se o incremento dos elementos norteadores da meditação para o campo educacional, mesmo porque a meditação já vem sendo praticada por estudantes em diversas escolas no mundo, sendo defendida cientificamente como uma contribuição eficaz para aumentar a concentração e diminuir o estresse e a ansiedade de

Suas principais funções são fazer parte do sistema límbico e coordenar quaisquer emoções, além de ser responsável pelo paladar (HERCULANO-HOUZEL, 2013). 
alunos nos diferentes níveis de educação. Ademais, tal prática tem sido associada à diminuição das distrações, e, concomitantemente, no aumento da concentração e relaxamento dos indivíduos que a praticam (ACARYA, 1995).

Como resultado da prática da meditação nos ambientes de ensino, também se pode elencar que essa vivência tem tido importância fundamental nos seguintes aspectos: rendimento acadêmico, na relação professor-aluno, nos trabalhos cooperativos discentes, na cognição, bem como na redução dos sintomas relacionados à ansiedade, estresse e demais distúrbios psicossomáticos. Estudos corroboram que o ato de meditar tem influenciado positivamente frente às dificuldades de aprendizagens que os alunos apresentam, estando intimamente interligadas a fatores como déficits de atenção, hiperatividade e ansiedade (CARVÃO, 2009; MORAES e BALGA, 2007).

Ressalta-se então, que todos esses benefícios gerados nas escolas são simplesmente essenciais para a apreensão dos conhecimentos outrora trabalhados, e para o desenvolvimento e manutenção de um ambiente mais harmonizado e tranquilo emocionalmente, pois, infelizmente sabe-se que as unidades escolares brasileiras nem sempre possuem essas características.

Convergindo para a prática meditativa do mindfulness, a qual serviu como instrumento de intervenção desta pesquisa, pode-se afirmar que o mindfulness é a resultância da tradução inglesa da palavra "Sati", em Pali, (língua original de Buda), que significa: recordar, consciência, intencionalidade da mente, mente vigilante, atenção plena, alerta e mente lúcida, se referindo a uma forma de prestar atenção de modo pleno nas diversas situações cotidianas, e estando caracterizada pela presença de três elementos essenciais:

- Atenção concentrada no momento presente;

- Intencionalidade;

- Ausência de julgamento. (KABAT-ZINN, 1990).

Kabat-Zinn (2005) detalha esses elementos descrevendo que concentrar-se no momento presente significa estar em contato puramente com o momento atual, livrando-se de recordações (ruminações) ou pensamentos futuros. Concentrar-se no momento atual é estar em contato com o presente e não embrenhado em recordações ou outros tipos ou fatos. Dessa maneira, o foco atencional é convertido apenas para o momento presente.

A intencionalidade faz referência ao esforço que o praticante faz para estar inteiramente atento ao estado mindfulness, visto que é comum durante as tentativas de gerar a atenção plena, os indivíduos divagarem automaticamente para situações alheias, como 
situações passadas/futuras ou relativas a estímulos que possam desconcentrá-los por um instante.

No domínio da intenção, os pensamentos, sentimentos, emoções e sensações devem ser observados na forma como se apresentam, não sendo classificados como positivos ou negativos, mas sim, meticulosamente observados como eles ocorrem. Sendo assim, o participante não julgará o que foi observado por ele, apenas, acolherá todas as experiências que lhes foram retroalimentadas mediante seu domínio atencional.

À medida que todo este processamento de prática de mindfulness for repetido, as reações a cada situação apresentada no cotidiano serão particulares e apropriadas para cada momento, fazendo com que se deixe de agir como um "piloto automático" (impulsos rígidos e inflexíveis) para se tornar mais compreensivo e complacente.

Nesse contexto, pode-se inferir que o principal objetivo das vivências de mindfulness reside nas tentativas de diminuir as reatividades mediante as inúmeras situações que são apresentadas neste mundo contemporâneo, procurando sempre manter um nível excelente de consciência e funcionamento psicológico, dialogando e realizando as tarefas com paz interior e coletiva.

Outro ponto relevante quanto às práticas de mindfulness são as riquezas sensoriais que as experimentações fornecessem, através de uma prática que não se vincula a uma determinada religião, pois objetiva essencialmente melhorar a capacidade de atenção como forma de aprimorar a autoconsciência cognitiva e emocional de seus praticantes.

Assim, tem-se a perspectiva de atuar com esses elementos do mindfulness no contexto educacional, visto que estudos já demonstraram que esta prática tem sido uma ferramenta muito importante para os professores utilizarem na ajuda aos estudantes em situação de risco, os quais muitas vezes estão sujeitos apenas a punições disciplinares, ao invés de serem trabalhados instrumentos preventivos que os ajudem no seu próprio crescimento emocional, atencional e regulativo (NAPOLI, 2004).

Dessa maneira, ao refletir com calma ante todas as alternativas possíveis, deixar-se-ia de agir de modo abrupto (piloto automático), e caminhar-se-ia para o fortalecimento de uma aprendizagem centrada em características mais holísticas, que darão condições de enxergar diversas situações cotidianas de modo diferente, criando, assim, novas perspectivas de ações, novas conexões neuronais e novas condutas cotidianas a partir das próprias experiências positivas (TANG e POSNER, 2009). 
Portanto, entende-se este trabalho como uma janela que se abre no ambiente escolar, em que, por meio dos corpos integrais, pode-se contribuir para a implantação de novas ações coletivas, para que assim possam ser ampliados os conhecimentos e a emancipação dos alunos a partir das práxis corporais inovadoras. Pode-se estabelecer, desta forma, uma nova linha de atuação frente às diversas situações apresentadas no dia a dia, abandonando as situações que trazem conflitos e partindo para um aprendizado incorporado.

\section{Metodologia}

Este estudo de tipologia pesquisa-ação, com abordagem quantitativo-qualitativa, foi realizado com estudantes do ensino médio integrado do Instituto Federal de Mato Grosso (IFMT), Campus Cuiabá - Bela Vista, tendo seu início a partir da aprovação do projeto no Comitê de Ética em Pesquisa da Universidade de Cuiabá (UNIC), em 13/09/2018, sob parecer $\mathrm{N}^{\circ} 2.892 .382$.

A amostra contou com a participação de 39 estudantes matriculados nos cursos de química e meio ambiente, com média de idade de 17,71 anos para os participantes do sexo masculino, e 17,68 anos para o público feminino. A ampla maioria da amostra foi representada pelo sexo feminino $82,06 \%$ (32 participantes); já o grupo masculino se consolidou com $17,94 \%$ da amostra (07 participantes).

Os estudantes participantes foram recrutados por livre adesão após ampla divulgação do projeto de pesquisa no campus. Como critério de exclusão, definiu-se que aqueles que apresentassem alguma doença grave não seriam selecionados para participar do programa; situação esta que seria identificada durante a aplicação da anamnese.

Para a produção dos dados foram utilizados: i) questionário sociodemográfico; ii) anamnese, iii) questionário perceptivo; iv) avaliação do nível de satisfação pós-vivências; v) instrumento recordatório; vi) pentáculo do bem-estar; e v) mensuração do peso e altura para a verificação do índice de massa corporal (IMC).

\section{Tabela 1 - Caracterização da amostra do estudo}

\begin{tabular}{lcc}
\hline & $\mathrm{N}=(7)$ & $\mathrm{N}=(32)$ \\
& Masculino & $17,68 \pm 0,84$ \\
\hline Idade & $17,71 \pm 1,03$ & $57,25 \pm 9,24$ \\
Peso $(\mathrm{kg})$ & $70,14 \pm 7,01$ & $1,61 \pm 0,63$ \\
Altura $(\mathrm{m})$ & $1,80 \pm 0,06$ & $22,12 \pm 3,28$ \\
\hline
\end{tabular}

Fonte: Dados da pesquisa. 
As intervenções que envolveram o módulo das vivências práticas de meditação mindfulness foram realizadas durante quatro encontros presenciais, entre os meses de março/abril de 2019, sendo estes executados uma vez por semana durante uma hora, proposta por um especialista na área, psicólogo e pesquisador de mindfullness, Leonardo Girotto de Oliveira, no auditório do referido campus.

Figura 1 - Vivência de Mindfulness no Campus Cuiabá - Bela Vista

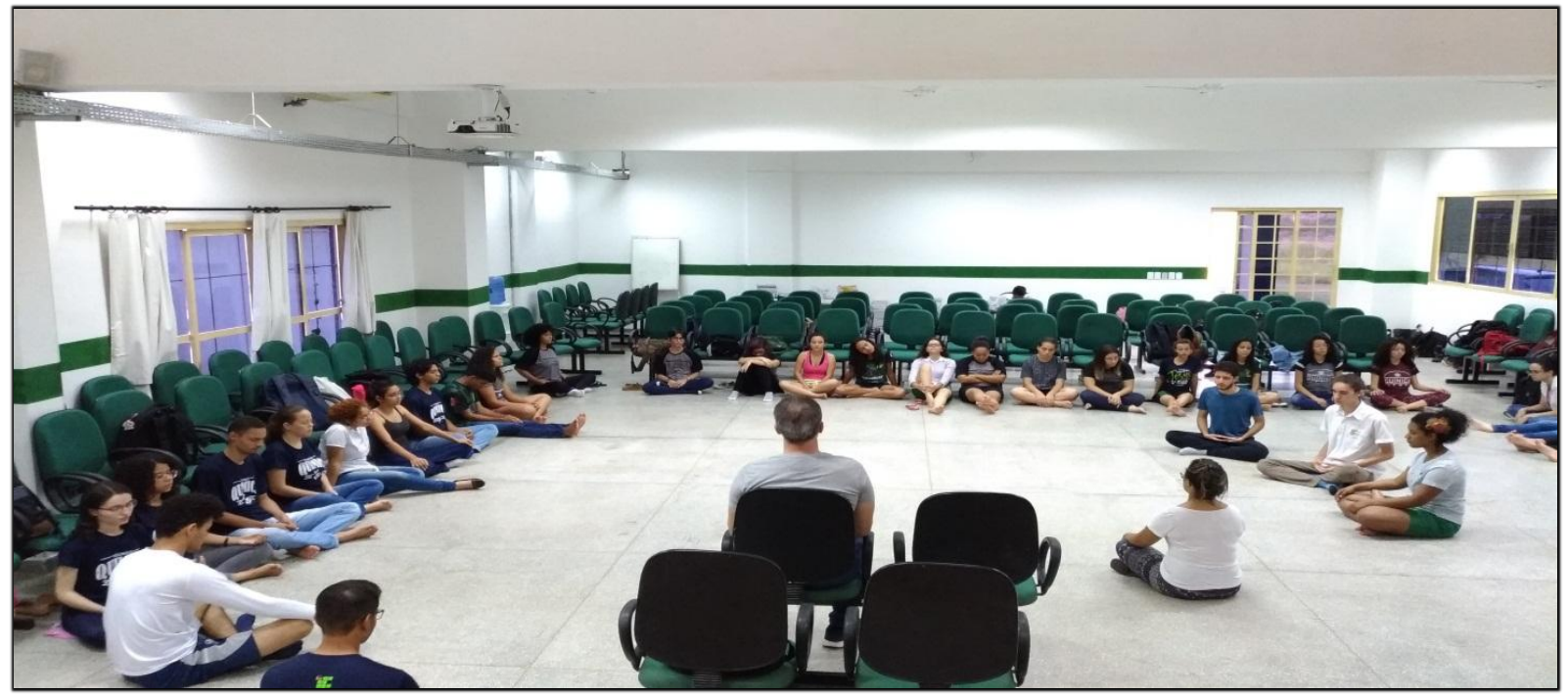

Fonte: Dados da pesquisa.

Como atividade complementar, foi solicitado aos participantes da pesquisa que continuassem a realizar as mesmas práticas desenvolvidas nos encontros presenciais, porém, durante oito semanas subsequentes em ambiente domiciliar. Tais atividades foram desenvolvidas com a utilização de instrumentos eletrônicos específicos para meditação mindfulness; neste caso, os aplicativos Lojong e Ácora, configurando assim, uma meditação mindfulness guiada (orientada pelo aplicativo).

Para a demonstração dos resultados quantitativos foi empregada a estatística descritiva e exploratória, utilizando índices absolutos, médias e desvio padrão. Quanto às percepções qualitativas dos investigados, estas foram transcritas a partir de um questionário aberto, cuja importância é evidenciada por Lüdke e André (1986); em que foi preservada a identidade dos envolvidos com a utilização do codinome "P" (Participante), seguido de um numeral (ex. "P 1"). Para a análise dos respectivos dados qualitativos, foi executada a triangulação entre aqueles produzidos nesta investigação, com os resultados de pesquisas similares, confrontados com autores consagrados da área. 


\section{Resultados}

Inicialmente são apresentados os relatos frente ao estado de saúde geral dos adolescentes participantes da pesquisa, que foram obtidos após a aplicação da anamnese, um dos primeiros instrumentos de produção de dados aplicados, cabendo ressaltar que os números apresentados se tratam apenas de relatos, e não diagnósticos realizados pela pesquisa em si. Contudo, entende-se que esses resultados evidenciaram uma situação preocupante que está inserida na vida dos alunos (as) e no ambiente escolar.

As informações apresentadas no gráfico 1, que podem ser cumulativas entre os indivíduos questionados, demonstram que 20 estudantes se sentem ansiosos em seus cotidianos; fato este que é caracterizado por expectativa de uma ameaça futura qualificada pelo sentimento de desconforto, em conjunto com a preocupação excessiva e o medo. Com relação ao estado psicossomático mais preocupante, que é a depressão, 5 estudantes afirmaram que convivem com esta doença.

Outro dado que chama a atenção evidencia que 10 desses participantes sofrem de enxaqueca, condição fisiológica que pode ser provocada por uma série de estímulos internos ou externos, como o estresse, a ausência de rotina para o sono, a alimentação inadequada, a exposição a ruídos altos, a fortes odores, ou até mesmo por variações dos níveis homeostáticos. Em contrapartida, um quantitativo de 16 estudantes afirmou não ter apresentado nenhum tipo de doença em suas vidas, o que representa cerca de $40 \%$ da amostra.

Os resultados obtidos harmonizam com o estilo de vida dos participantes verificado na pesquisa, que mostraram que $51 \%$ destes adolescentes apresentam características sedentárias, pois não praticam pelo menos 30 minutos de atividades físicas moderadas ou intensas por cinco dias consecutivos ou intervalados durante o período de uma semana. 
Gráfico 1 - Relato do estado de saúde dos participantes da pesquisa

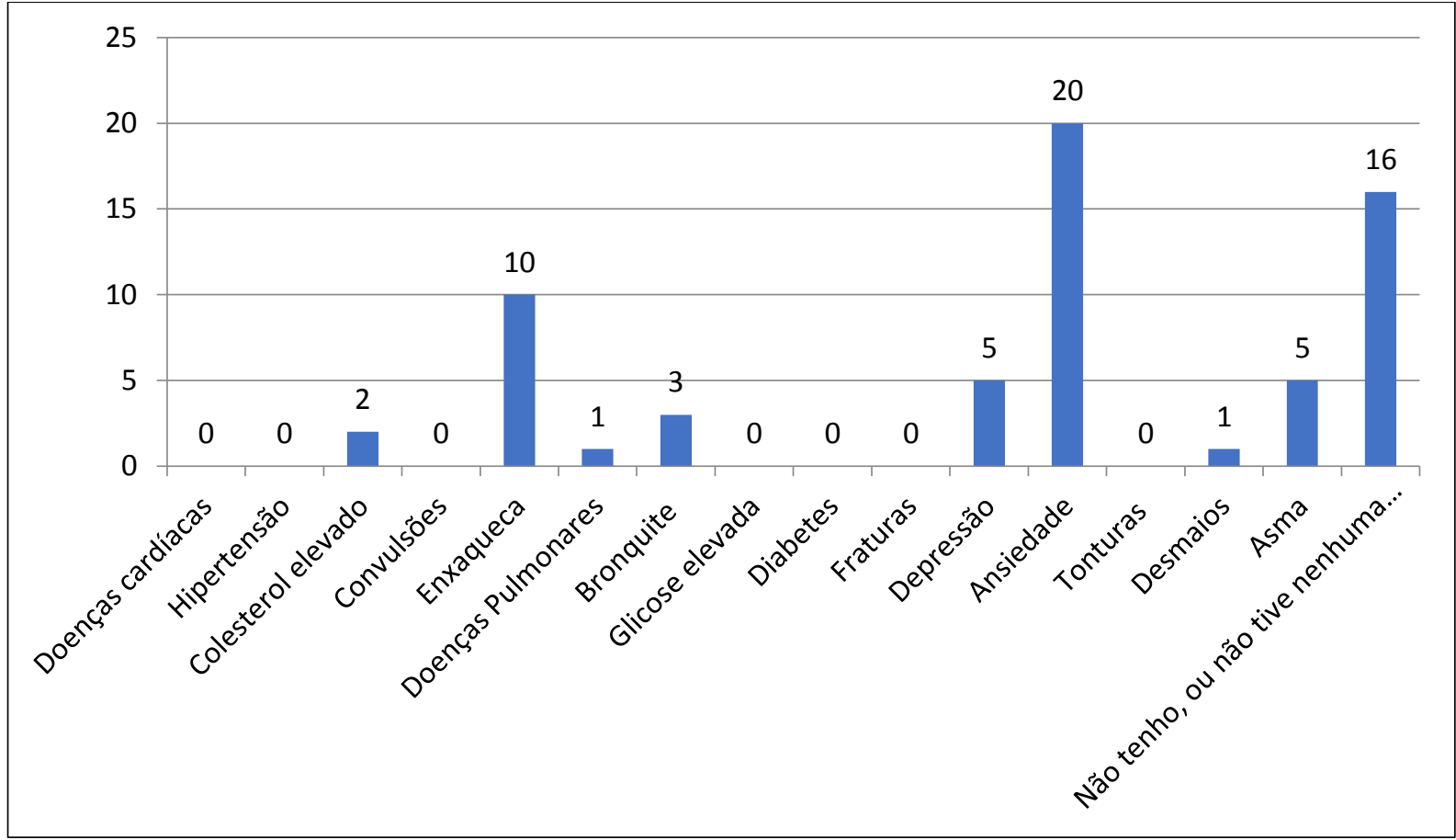

Fonte: Dados da pesquisa.

No que se refere à prática intervencionista do estudo, que fomenta à profunda reflexão sobre as ações do corpo integral no cotidiano escolar e fora dele, verificou-se que os estudantes realizaram as práticas de modo presencial (escola) e no ambiente domiciliar de forma satisfatória, atingindo uma média de $(8,10 \pm 7,35)$ práticas de mindfulness efetuadas, conforme registrado no gráfico 2; no qual o eixo horizontal (x) representa o número total de participantes do estudo $(\mathrm{N}=39)$, e o eixo vertical (y) evidencia o quantitativo máximo de práticas meditativas realizadas individualmente.

Gráfico 2 - Quantitativo de meditações mindfulness praticadas nas residências dos participantes

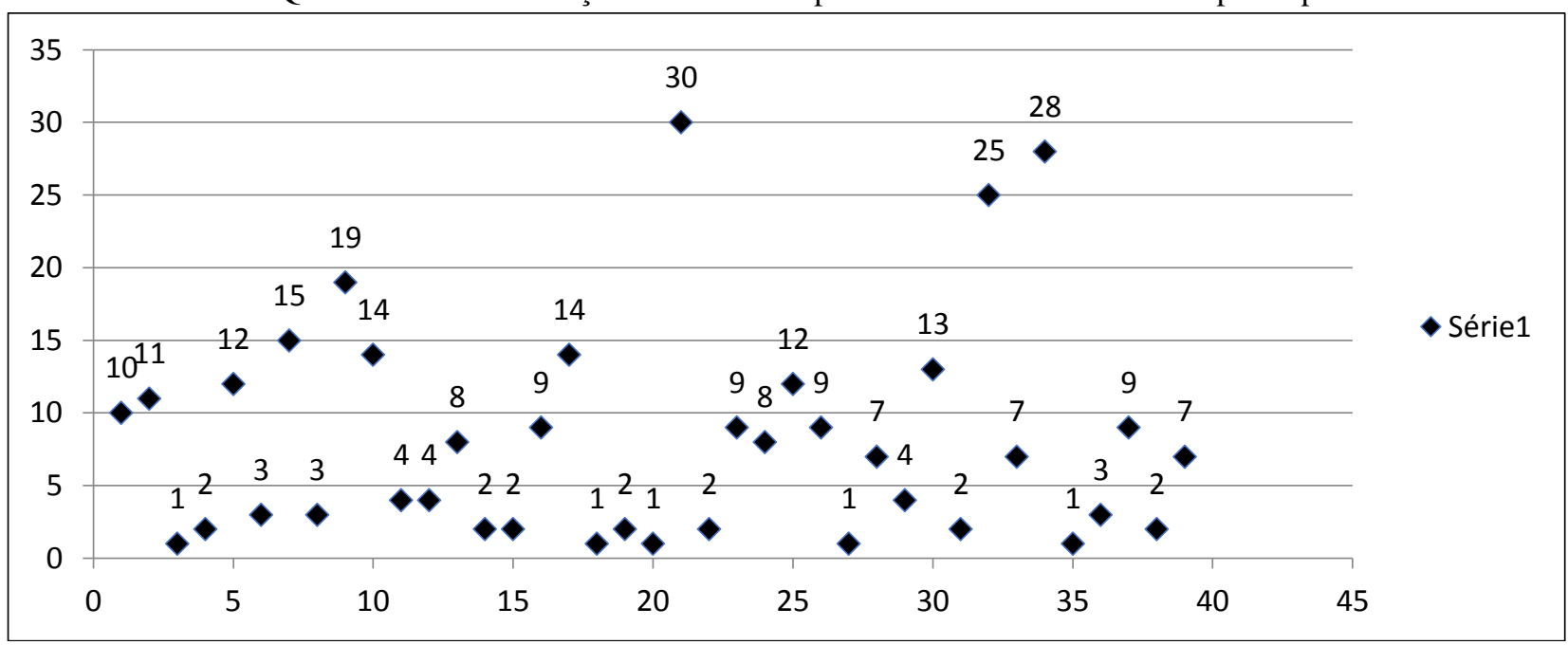

Fonte: Dados da pesquisa. 
Já o gráfico 3 aponta que os participantes se mostraram satisfeitos com este tipo de vivência, avaliando-as em sua ampla maioria como "ótimas". Além disso, demonstrou-se esse nível de satisfação dos estudantes pós-vivências, mediante a transcrição de alguns relatos dos participantes do programa.

Gráfico 3 - Nível de satisfação pós-vivências de meditação mindfulness

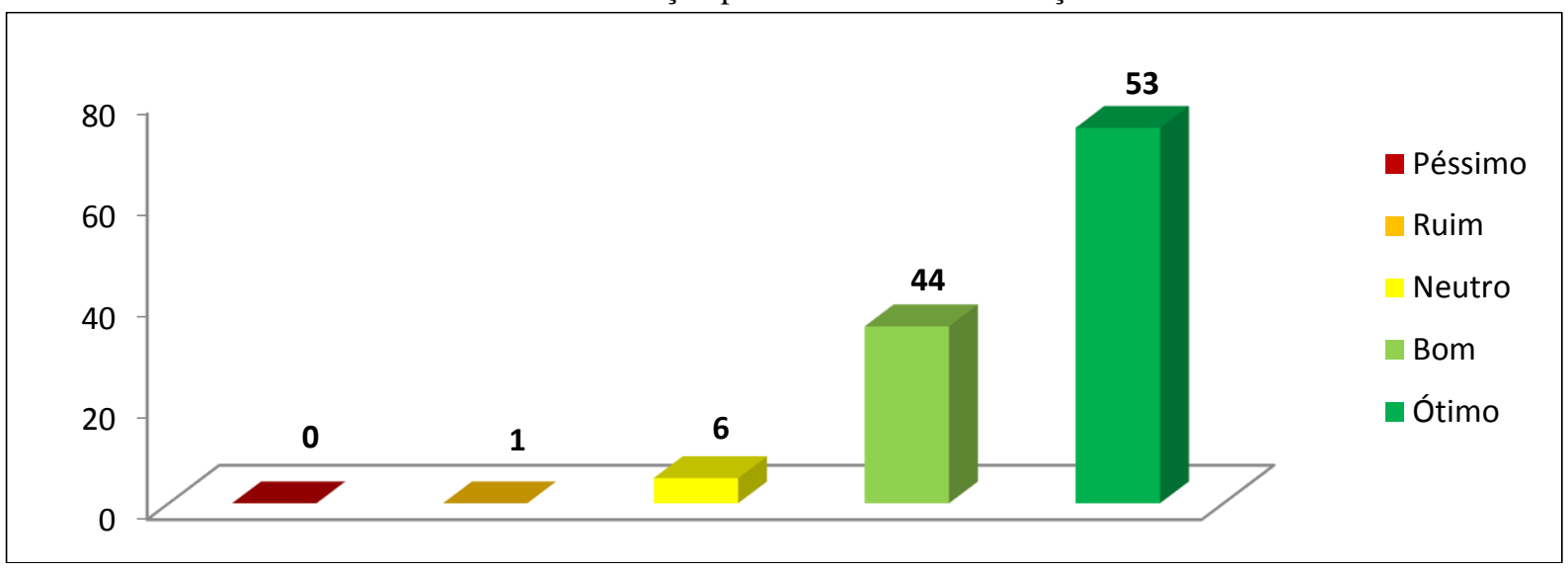

Fonte: Dados da pesquisa.

Fatores relativos à percepção corporal, ao comportamento individual/coletivo e à avaliação pós-realização das atividades práticas se constituíram como elementos fundamentais para se verificar opiniões dos participantes do estudo.

O quadro 1 traz importantes depoimentos que ratificam a importância desse tipo de intervenção no ambiente escolar, e para o dia a dia desses indivíduos.

Quadro 1 - Percepções dos participantes do programa pós-vivências de mindfulness

\begin{tabular}{|c|c|}
\hline \multirow{5}{*}{ Percepção corporal } & "Simmm, eu tô mais calma, tomando decisões pensadas, atenção melhor". (P1). \\
\hline & $\begin{array}{l}\text { "Sim, eu tenho uma visão diferente do meu corpo, ele é como um templo, } \\
\text { através dele, cuidando dele, conhecendo ele, nós conseguimos melhoras } \\
\text { diversas áreas da nossa vida". (P2). }\end{array}$ \\
\hline & $\begin{array}{l}\text { "Sim, agora vejo que meu corpo é além dos padrões de beleza, que ele é como } \\
\text { uma moradia, onde posso unir com a minha mente e relaxar". (P3). }\end{array}$ \\
\hline & $\begin{array}{l}\text { "Sim, percebi como posso controlar meu corpo e minhas emoções, através } \\
\text { dele". (P4). }\end{array}$ \\
\hline & "Sim, pois estou mais consciente do meu corpo e da minha mente". (P5). \\
\hline \multirow{4}{*}{$\begin{array}{l}\text { Comportamento } \\
\text { pessoal/coletivo }\end{array}$} & $\begin{array}{l}\text { "Sim, após o início das realizações das práticas consegui me tornar mais calma } \\
\text { em algumas situações, me concentrar no momento presente e pensar um pouco } \\
\text { mais em minhas ações e como isso gera impacto sobre meu próprio organismo". } \\
\text { (P6). }\end{array}$ \\
\hline & $\begin{array}{l}\text { "Sim, me proporcionou melhoria na atenção, melhoria no relacionamento, } \\
\text { estou mais calma, mais ouvinte". (P7). }\end{array}$ \\
\hline & $\begin{array}{l}\text { "Percebi que penso mais antes de fazer ou falar algo e a não me importar tanto } \\
\text { com coisas pequenas do cotidiano acadêmico que antes me deixariam muito } \\
\text { estressada". (P8). }\end{array}$ \\
\hline & $\begin{array}{l}\text { "O mindfulness me ajudou a me manter mais calma quando estava com muitas } \\
\text { pessoas. era uma coisa na qual eu tinha dificuldade". (P9). }\end{array}$ \\
\hline
\end{tabular}




\begin{tabular}{|c|c|}
\hline & $\begin{array}{l}\text { "Como sou uma pessoa mais tímida, sempre foquei muito nas pessoas à minha } \\
\text { volta, com o mindfulness, por exemplo, passei a focar em outras coisas mais } \\
\text { positivas sobre mim e as pessoas, o que tem me ajudado a "me soltar"”. (P10). }\end{array}$ \\
\hline \multirow{5}{*}{ Avaliação do estudo } & $\begin{array}{l}\text { "É um projeto muito válido para os jovens. normalmente nós não sabemos bem } \\
\text { como lidar com diversas questões que, de qualquer forma, estarão inseridas na } \\
\text { nossa vida. acredito que pensar em uma forma de nos ajudar a viver melhor e } \\
\text { passar dias mais tranquilos e produtivos seja revolucionar os projetos dentro } \\
\text { das escolas". (P11). }\end{array}$ \\
\hline & $\begin{array}{l}\text { "O estudo foi muito eficaz e deve ser implementado nas escolas, pois creio que } \\
\text { como eu, outros alunos conseguirão lidar com seus problemas e stress } \\
\text { cotidianos com meios alternativos e saudáveis". (P12). }\end{array}$ \\
\hline & "Eu amei me ajudou a me manter focada e a não me estressar por tudo". (P13). \\
\hline & $\begin{array}{l}\text { "Eu achei incrível, as atividades foram ótimas e ajudou muito. É algo que devia } \\
\text { ser de mais fácil acessibilidade para todos os alunos, as escolas podiam } \\
\text { proporcionar isso, da mesma forma que as empresas têm que fornecer a } \\
\text { ginástica laboral". (P14). }\end{array}$ \\
\hline & $\begin{array}{l}\text { "Importante, pois me auxiliou nas minhas crises de ansiedade, principalmente } \\
\text { na respiração". (P15). }\end{array}$ \\
\hline
\end{tabular}

Fonte: Dados da pesquisa.

\section{Discussões}

Os resultados demonstrados neste estudo exprimem a relevância do ato de refletirmos sobre nós mesmos e agirmos conscientemente após essas análises. Através da integralização corpo-mente no ambiente escolar possibilitou-se aos estudantes observarem alguns préconceitos e rotinas cotidianas, que vêm sendo enraizados em suas jornadas acadêmicas, laborais e pessoais, neste mundo contemporâneo.

As influências negativas e demasiadas advindas do mundo tecnológico-virtual passam a ser observadas/analisadas como mais intimidade, tornando-se essas ações de discussão/enfrentamento elementos fundamentais para a superação de tudo aquilo que está sendo imposto repentinamente na sociedade, que causa, por vezes, inúmeros distúrbios psicossomáticos numa população que mal viveu sua infância, e já se encontra num mundo demasiadamente acelerado e opressor.

Estudos realizados por Hard et al., (2012) elucidam que existe íntima relação entre a prática da meditação mindfulness com a saúde corpo-mente de seus praticantes, o que diminui por consequência as variáveis negativas ocasionadas pelo estresse e pelos distúrbios mentais. Numa via oposta, gera-se o aumento concomitante dos sistemas de atenção, autocontrole, bemestar, e na clareza dos pensamentos/ações cotidianas (WALSH e SHAPIRO, 2006).

Neste sentido, observa-se que são produzidos efeitos biológicos positivos por meio da prática contínua da meditação mindfulness, em que se reduz sensivelmente agentes estressores, como por exemplo, níveis hormonais de cortisol elevados. É o que revelou um estudo de quatro 
semanas com estudantes universitários que praticaram este tipo de meditação, quando comparados ao grupo controle (FAN et al., 2014).

Outra pesquisa conduzida por Schonert-Reichl et al., (2015) corroborou que escolares que participaram de intervenções de mindfulness apresentaram avanços cognitivos, emocionais e melhores tomadas de decisões cotidianas, diminuindo em contrapartida, aspectos relacionados ao estado de tristeza, depressão, estresse e agressividade (comportamento reativo). Tal suspeita também é corroborada por outros resultados que evidenciam diminuições nos níveis de ruminação em meditadores, quando comparados a indivíduos não meditadores (GUENDELMAN; MEDEIROS; RAMPES, 2017).

Já investigações norte-americanas, conduzidas pela Havard Medical School (2011), revelaram aumento de massa cinzenta no cérebro de praticantes de mindfulness, sendo as regiões corticais mais envolvidas aquelas relacionadas à aprendizagem, memória e emoções. Opostamente, Hölzel et al., (2009) evidenciaram uma correlação entre a redução da percepção de estresse, com uma menor densidade de massa cinzenta na região direita do cérebro.

Trazendo então esse contexto para a perspectiva acadêmica, pressupõe-se que não apenas o público discente será beneficiado com este tipo de programa interventivo. Todo o amplo ambiente escolar é agraciado com melhoras pessoais, sociais, físicas e cognitivas, conforme evidenciam outros diversos estudos (HUPPERT \& JOHNSON, 2010; KUYKEN ET AL., 2013; ZENNER ET AL., 2014).

Em síntese, as investigações no mundo apontam que, quando um dos agentes envolvidos nos ambientes acadêmico-formativos se comporta de maneira atenta e equilibrada emocionalmente, os indivíduos a sua volta passam a adotar o mesmo tipo de comportamento (HUPPERT e JOHNSON, 2010).

Especificamente no Brasil, poucos estudos/investigações são realizados acerca desta temática, porém, observa-se, num contexto geral, que as intervenções meditativas em ambientes escolares trazem melhoras para a saúde mental e qualidade de vida geral dos estudantes em curto-médio prazo (OVÍDIO, 2016).

Nesse sentido, buscou-se fomentar neste trabalho um ambiente que possa aliar a prática intrapessoal e reflexiva aos adolescentes/jovens em ambiente escolar, para que estes possam manter condutas de enfrentamento aos diversos problemas de saúde aos quais estão expostos, de modo que, tais conceitos e atitudes também possam colaborar em suas rotinas acadêmicas, em favor da aquisição do conhecimento. 


\section{CONSIDERAÇÕEs FinAis}

A proposta de se intensificar a experimentação e a unicidade corpo-mente por meio da prática da meditação mindfulness, neste trabalho, consistiu-se em promover a saúde físicoemocional aos estudantes do ensino médio integrado no ambiente de uma escola profissionalizante, na qual, por meio de atividades práticas, eles puderam vivenciar e desfrutar atividades de autoconhecimento, relaxamento e concentração. Esses benefícios se constituem a base da atenção plena e das relações intra e interpessoais, que devem se conjecturar para o completo sucesso das formações individuais e acadêmicas.

Nesta perspectiva, foram unidas ações de escolares protagonistas que se coadunaram com os objetivos educacionais, os quais, de forma sensível, responsável, autônoma, crítica e dialética, desenvolveram reais situações de enfrentamento aos riscos à sua saúde geral, bem como, encontraram novas maneiras de reagir frente aos inúmeros estímulos negativos que os perpassam atualmente, inclusive nas escolas.

Os resultados desta pesquisa, ainda que parciais, pois este estudo tratou-se apenas de um recorte de uma pesquisa maior em nível de mestrado, se mostraram satisfatórios e benéficos, de acordo com os dados e relatos perceptivos apresentados pelos estudantes do ensino médio em questão. Eles destacam o quão foi inovador e importante vivenciar este tipo de atividade na escola, ainda mais porque muitos deles já apresentam indícios de doenças psicossomáticas graves, que podem se tornar crônicas num breve futuro caso nada for feito.

Contudo, cabe aqui fazer uma ressalva a todos os agentes que fazem parte do amplo sistema educativo de nosso país, pois às vezes o próprio ambiente escolar e seu coletivo de pessoas, juntamente com o mundo tecnológico/virtual desenfreado em que se vive hoje, são os potenciais agentes estressores que acabam por contribuir para que nos afastemos de nós mesmos quase que instantaneamente, gerando grandes dificuldades para que os caminhos futuros possam ser percorridos.

Nesse sentido, é necessário ampliar coletivamente esse tipo de experiência em ambiente escolar, para que, a partir de atividades somáticas integrais (como a meditação mindfulness), seja possível formar uma rede de convivência e experiências socioculturais que se estabeleçam entre parcerias inovadoras, articuladas e afáveis, a fim de que se organize todo um ambiente que é importantíssimo para a solidificação de indivíduos atentos, reflexivos e exponenciais, em suas atividades futuras na sociedade. 


\section{REFERÊNCIAS}

ACARYA, Avadhutika Anandamitra. Yoga para a saúde. São Paulo: Ananda Marga, 1995.

CARVÃO, Regina Célia Bezerra. Oração e Meditação: Duas Práticas no Enfrentamento de Doenças. Monografia (Especialização em Psicologia Transpessoal) - Centro Educacional de Blumenau \& ALUBRAT. Campinas, 2009. Disponível em:

<http://docplayer.com.br/6740971-Duas-praticas-no-enfrentamento-de-doencas.html>

Acessado em: 23 mai. 2019.

DANUCALOV, Marcello Arias Dias; SIMÕES, Roberto Serafim. Neurofisiologia da Meditação. São Paulo: Phorte, 2006.

FAN, Yaxin; Tang, Yi-Yuan; Posner, Michael. Cortisol level modulated by integrative meditation in a dose-dependent fashion. Stress Health, v. 30, n. 1, p. 65-70, 2014. Disponível em: <https://onlinelibrary.wiley.com/doi/abs/10.1002/smi.2497>. Acessado em 20 mai. 2019.

GEBARA, A. Educação Física \& Esportes: Perspectivas para o século XXI. Campinas: Papirus, 1992.

GUENDELMAN, Simón; MEDEIROS, Sebastián; RAMPES, Hagen. Mindfulness and emotion regulation: Insights from neurobiological, psychological, and clinical studies.

Frontiers in Psychology, v. 8, p. 1-23, 2017. Disponível em:

$<$ https://www.frontiersin.org/articles/10.3389/fpsyg.2017.00220/full>. Acessado em 29 mai. 2019.

HARDT, Jochen; SCHULTZ, Sonja; XANDER, Carola; BECKER, Gerhild. \& DRAGAN, Malgorzata. The Spirituality Questionnaire: Core Dimensions of Spirituality. Psychology, v. 3, p. 116-122, 2012. Disponível em:

$<$ https://www.researchgate.net/publication/228521274_The_Spirituality_Questionnaire_Core Dimensions_of_Spirituality>. Acessado em 13 mai. 2019.

HERCULANO-HOUZEL, Suzana. O cérebro adolescente. A neurociência da transformação da criança em adulto. eBook Kindle, 2013.

HÖLZEL, Britta; CARMODY, James; EVANS, Karleyton, HOGE, Elizabeth; DUSEK, Jeffery; MORGAN, Lucas; PITMAN, Roger; LAZAR, Sara. Stress reduction correlates with structural changes in the amygdala. Social Cognitive and Affective Neuroscience, v. 5, n. 1, p. 11-17, 2009. Disponível em: 〈https://www.ncbi.nlm.nih.gov/pmc/articles/PMC2840837/>. Acessado em 25 mai. 2019.

HUPPERT, Felicia A; JOHNSON, Daniel M. A controlled trial of mindfulness training in schools: The importance of practice for an impact on well-being. The Journal of Positive Psychology, v.5 n. 4, p. 264-274, 2010. Disponível em:

<https://www.tandfonline.com/doi/abs/10.1080/17439761003794148>. Acessado em 18 mai. 2019.

JENSEN, Frances. O Cérebro Adolescente: Guia de sobrevivência para criar adolescentes e jovens adultos. Rio de Janeiro: Intrínseca, 2016. 
KABAT-ZINN, Jon. Full Catastrophe Living: Using the Wisdom of your Mind to Face Estresse, Pain and Illness. New York: Dell Publishing, 1990.

KABAT-ZINN, Jon. Comming to our senses: Healing ourselves and the world through mindfulness. New York: Hyperion, 2005.

KRISTEVA, Julia. As novas patologias da alma. Rio de Janeiro: Rocco, 1995.

KUYKEN, Willem; WEARE, Katherine; UKOUMUNNE, Obioha; VICARY, Rachael. Effectiveness of the Mindfulness in Schools Programme: non-randomised controlled feasibility study. The British Journal of Psychiatry, v. 203, n. 2, p. 126-131, 2013. Disponível em: <https://www.cambridge.org/core/journals/the-british-journal-ofpsychiatry/article/effectiveness-of-the-mindfulness-in-schools-programme-nonrandomisedcontrolled-feasibility-study/BEB4925E41DEB31345A4FB14FA264A09>. Acessado em 30 mai. 2019.

LAZAR, Sara; WASSERMAN, Rachel; TREADWAY, Michael. Meditation experience is associated with increased cortical thickness. Neuroreport, v. 16, n.17, p. 1893-1897, 2005. Disponível em: 〈https://www.ncbi.nlm.nih.gov/pmc/articles/PMC1361002/>. Acessado em 12 mai. 2019.

LEVINE, Noah. The Heart of the Revolution: The Buddha's Radical Teachings on Forgiveness, Compassion, and Kindness. HarperOne, 2011.

LEVISKY, David Leo. Adolescência: reflexões psicanalíticas. Porto Alegre: Artes Médicas, 1995.

LÜDKE, Menga; ANDRÉ, Marli E. D. A. Pesquisa em educação: abordagens qualitativas. São Paulo: EPU, 1986.

MARQUES, Luciana Fernandes; ROCHA, Mariana Duarte; FLORES, José Francisco. Fundamentos da meditação no ensino básico: transdisciplinaridade, holística e educação integral. NUPEAT-IESA-UFG, v 5, n 2, p. 398-413, 2015. Disponível em: <https://revistas.ufg.br/teri/article/view/38797>. Acessado em 15 mai. 2019.

MORAES, Fabiana Oliveira; BALGA, Rômulo Sangiorgi Medina. A yoga no ambiente escolar como estratégia de mudança no comportamento dos alunos. Revista Mackenzie de Educação Física e Esporte, v. 6, n. 3, p. 59-65, 2007. Disponível em:

$<$ http://editorarevistas.mackenzie.br/index.php/remef/article/view/1227/938>. Acessado em 27 mai. 2019.

MORAES, Maria Cândida. Pensamento Eco-sistêmico: educação, aprendizagem e cidadania no século XXI. Petrópolis: Vozes, 2005.

NAPOLI, Maria. Mindfulness Training for Teachers: A Pilot Program. Complementary Health Practice Review, v. 9, p. 31-42, 2004. Disponível em: <https://www.researchgate.net/publication/244918670_Mindfulness_Training_for_Teachers A_Pilot_Program>. Acessado em 27 mai. 2019. 
NEWBERG, Andrew B.; IVERSEN, Jeremy. The neural basis of the complex mental task of meditation: neurotransmitter and neurochemical consid-erations. Medical Hyotheses, v. 61, n. 2, p. 282-291, 2003. Disponível em:

<https://www.sciencedirect.com/science/article/abs/pii/S0306987703001750>. Acessado em 17 mai. 2019.

OMS. Organização Mundial da Saúde. Estratégias de la OMS para a medicina tradicional 2002-2005. Disponível em:

<http://www.dominiopublico.gov.br/download/texto/op000023.pdf >. Acessado em: 22 mai. 2019.

OVÍDIO, Waldemar; RIGATTI, Roberta; MENEZES, Carolina; GUIMARÃES, Gabriela; FACETO, Olga; HELDT, Elizet. Impact of a combined mindfulness and social-emotional learning program on fifth graders in a Brazilian public school setting. Psychology \&

Neuroscience, v. 9, n. 1, p. 79-90, 2016. Disponível em:

<https://psycnet.apa.org/record/2016-16351-007>. Acessado em 11 mai. 2019.

SCHONERT-REICHL, Kimberly; OBERLE, Eva; LAWLOR, Molly Stwart; ABBOTT, David; THOMSON Kimberly; OBERLANDER, Tim; DIAMOND, Adele. Enhancing cognitive and social-emotional development through a simple-to administer mindfulnessbased school program for elementary school children: A randomized controlled trial.

Developmental Psychology, v. 51, p. 52-66, 2015. Disponível em:

<https://psycnet.apa.org/record/2014-56463-002>. Acessado em 25 mai. 2019.

SHAPIRO, Deane; WALSH, Roger. Meditation. New York: Aldine Transaction, 1984.

TANG, Yi-Yuan; POSNER, Michael. Attention training and attention state training. Trends in Cognitive Sciences, v. 13, n. 5, p. 222-227, 2009. Disponível em:

<https://www.cell.com/trends/cognitive-sciences/fulltext/S1364-6613(09)00075-8>. Acessado em 15 mai. 2019.

THE HAVARD GAZETTE. Eight weeks to a better brain, (HEALTH \& MIDICINE), 2011. Disponível em: <https://news.harvard.edu/gazette/story/2011/01/eight-weeks-to-abetter-brain/> Acessado em: 23 mai. 2019.

VALE, Nilton. Bezerra. Analgesia adjuvante e alternativa. Revista Brasileira de Anestesiologia, v. 56 n. 5, p. 30-555, 2006. Disponível em:

$<$ http://www.scielo.br/scielo.php?pid=S0034-

70942006000500012\&script=sci_abstract\&tlng=pt> Acesso em: 17 set. de 2018.

VALLATH, Nandini. Perspectives on Yoga inputs in the management of chronic pain Consultant - Bangalore Institute of Oncology. Indian J Palliat Care, v. 16, n. 1, p. 1-7, 2010. Disponível em: < https://www.ncbi.nlm.nih.gov/pubmed/20859464>. Acessado em 20 set. 2018.

ZENNER, Charlotte; HERRNLEBEN-KURZ, Solveig; WALACH, Harald. Mindfulnessbased interventions in schools-A systematic review and meta-analysis. Front Psychol, v. 5, p. 603, 2014. Disponível em: 〈https://www.ncbi.nlm.nih.gov/pmc/articles/PMC4075476/>. Acessado em 28 mai. 2019. 
WALSH, Roger; SHAPIRO, Shauna. The meeting of meditative disciplines and western psychology. A mutually enriching dialogue. American Psychologist, v.61, n. 3, p. 227-239, 2006. Disponível em: <https://psycnet.apa.org/search/results?id=8665c225-b173-6f70-4b2bb703e97bdb61>. Acessado em 23 mai. 2019.

Recebido em: 13 de agosto de 2019. Aprovado em: 07 de dezembro de 2019. 